\title{
Association of DNA with nuclear matrix in in vitro as- sembled nuclei induced by rDNA from Tetrahymena shang- haiensis in Xenopus egg extracts
}

Chen Ying, Bo ZHANG, Xiu Fen LI, Zhong He ZHAI

Department of Cell Biology and Genetics, College of Life Sciences, Peking University, Beijing 100871

\begin{abstract}
The nuclei assembled from exogenous DNA or chromatin in egg extracts resemble their in vivo counterparts in many aspects. However, the distribution pattern of DNA in these nuclei remains unknown. We introduced rDNA from the macronuclei of Tetrahymena into Xenopus cellfree extracts to examine the association of specific DNA sequences with nuclear matrix (NM) in the nuclei assembled in vitro. Our previous works showed the 5'NTS (nontranscription sequences) of the rDNA specifically bind to the NM system in the macronuclei. We show now the rDNA could induce chromatin assembly and nuclear formation in Xenopus cell-free system. When we extracted the NM system and compared the binding affinity of different regions of rDNA with the NM system, we found that the 5'NTS still hold their binding affinity with insoluble structure of the assembled nuclei in the extracts of Xenopus eggs.
\end{abstract}

Key words: Nuclear assembly, nuclear matrix, Xenopus egg extracts, Tetrahymena rDNA.

On the occasion of Professor Lu Ji SHI's (L. C. Sze), eightieth birthday, we present this paper and extend our sincere greetings to Professor SHI.

As we mentioned in our paper, in early 1950's, it is Professor SHI who first studied the behavior of exogenous homologous desoxyribose nucleoprotein (chromatin) in amphibian eggs. His work later led to the study of nuclear assembly in cell-free system. No words can be said too much to describe Professor SHI's achievements in this field.

Since the beginning of our research in this field in 1989, Professor SHI always shows high interests in our work, exchanges ideas with us and encourages us. We want to express our deep indebtedness to Professor SHI for his many kindness. 
rDNA and nuclear matrix

\section{INTRODUCTION}

Early research found that after the removal of DNA and high-salt extraction of chromosomal from mouse liver nuclei, some residual insoluble proteins remained and assumed to constitute a skeleton, to which DNA is fixed. Later the term "nuclear matrix (NM)" was introduced, and the idea that the involvement of nuclear matrix in the spatial organization of eukaryotic genome steadily gained support[1]. As well as others, our previous work also demonstrated that specific DNA regions have binding affinity to the nuclear matrix, and this kind of binding is essential for many other important biological activities, such as DNA replication and RNA transcription[2, $3]$.

As early as 1959, Sze et al. microinjected exogenous DNA into amphibian eggs, and found the formation of chromatin and nuclear like structure around the added DNA[4]. In 1980s, Lohka, Masui and Newport et al found that nuclear-like structure could form from exogenous protein-free DNA or chromatin incubated in the extract from Xenopus eggs [5, 6]. Since then, many research works have demonstrated the extracts from Xenopus eggs is a useful cell-free system in the study of nucleus. The assembled nuclei resemble eukaryotic nuclei in vivo in many aspects, such as DNA replication, protein transportation through nuclear pore complexes. The formation of nucleosomes and chromatin structure was also reported in previous works [3, 7, 8]. However the distribution pattern of DNA in these nuclei remains unknown. Cai showed there exists a nuclear matrix system in the in vitro assembled nucleus[9]. So we wonder if this nuclear matrix contributes to the distribution of chromatin in the reassembled nucleus, and to the regulation of transcription and replication.

Therefore, we chose the rDNA of macronuclei from Tetrahymena shanghaiensis as exogenous DNA to induce nuclear assembly in Xenopus egg extracts and studied its distribution pattern in the assembled nuclei. T. shanghaiensis ribosomal DNA (rDNA) is a fairly small $(21 \mathrm{~kb})$, linear chromosome, which is a good model template for the study of chromosomal elements. The association of ribosomal gene with insoluble residual structure in vivo had been reported in several studies[10, 11]. And further study also demonstrated that the non transcribed spacers(NTS) flanking the coding region serve as anchorage sites for the whole ribosomal gene transcription unit in rat[12]. Luo et al also demonstrated that the 5'-NTS and telomere of rDNA of $T$. shanghaiensis have high association affinity with the NM system in the macronuclei of T. shanghaiensis[13]. These works provided us good opportunity to compare the rDNA distribution pattern in in vitro assembled nuclei with that in vivo.

Here we report the association of rDNA of $T$. shanghaiensis with the assembled nuclear matrix in the cell-free system. The association affinity of different regions of rDNA was also compared. We found that the region of the rDNA binding to the residual insoluble structure of the assembled nuclei in the extract of Xenopus eggs was localized in the 5'-NTS flanking the transcriptional region. 


\section{MATERIALS AND METHODS}

\section{Cell culture and rDNA extracts and purification}

\section{Cell culture}

Tetrahymena shanghaiensis so. nor. was provided by late Prof. Yuezhen CHEN[14], College of Life Sciences of Peking University. They were cultured in 2\% PPYS: $2 \%$ Protease peptone (Oxoid), $0.5 \%$ yeast extracts (Oxoid), $0.1 \%$ glucose. Ordinary experimental culture is immersed in a water bath at $27{ }^{\circ} \mathrm{C}$ with gentle shaking $(150 \mathrm{rpm})$.

\section{rDNA isolation and purification}

The rDNA was isolated and purified with the method established by T. Cech[15]. Cells were harvested from $250 \mathrm{ml}$ cultures by centrifugation at $1000 \mathrm{~g}$ for $8 \mathrm{~min}$, and washed in $50 \mathrm{ml}$ washing buffer $(0.75 \mathrm{M} \mathrm{NaCl}, 0.1 \mathrm{M}$ EDTA, pH 7.5) by resuspending and pelleting at $1000 \mathrm{~g}$ for $10 \mathrm{~min}$. The cells were resuspened in 1-2 ml washing buffer, then mixed with $15 \mathrm{ml}$ phenol-m-cresol solution at $60{ }^{\circ} \mathrm{C}$ for $5 \mathrm{~min}$ with gentle shaking, then $4-5 \mathrm{ml}$ chloroform was added while shaking for another $3 \mathrm{~min}$ at $60{ }^{\circ} \mathrm{C}$. The mixture was centrifuged at $23,000 \mathrm{~g}$ for $30 \mathrm{~min}$ at $20{ }^{\circ} \mathrm{C}$. The supernatant was extracted with phenol: chloroform and DNA was precipitated with ethanol.

The nuclear acids were dissolved in $1 \mathrm{ml}$ TE (10 mM Tris-HCl, $1 \mathrm{~m} M$ EDTA, pH 8.0) containing RNAase $(20 \mu \mathrm{g} / \mathrm{ml})$, then the DNA can be purified with electroelution in dialysis bag.

\section{Preparation of probes}

In our experiments, different Hind III digested fragments of rDNA were used as probes for in situ hybridization and dot hybridization. Most of rDNA recombined together in pBR322 as plasmid pRD4-I (Fig 1). The plasmid was gift from Prof. E. Blackburn (UCSF). pRd4-1 was digested with endonuclease Hind III, after electrophoresis, rRNA gene fragments $(4.2 \mathrm{~kb}, 2.2 / 2.1 \mathrm{~kb}$ and $1.6 \mathrm{~kb})$ were recovered and labeled with ll-biotin-dATP or ${ }^{32} \mathrm{P}$-dCTP by random primer labelling.

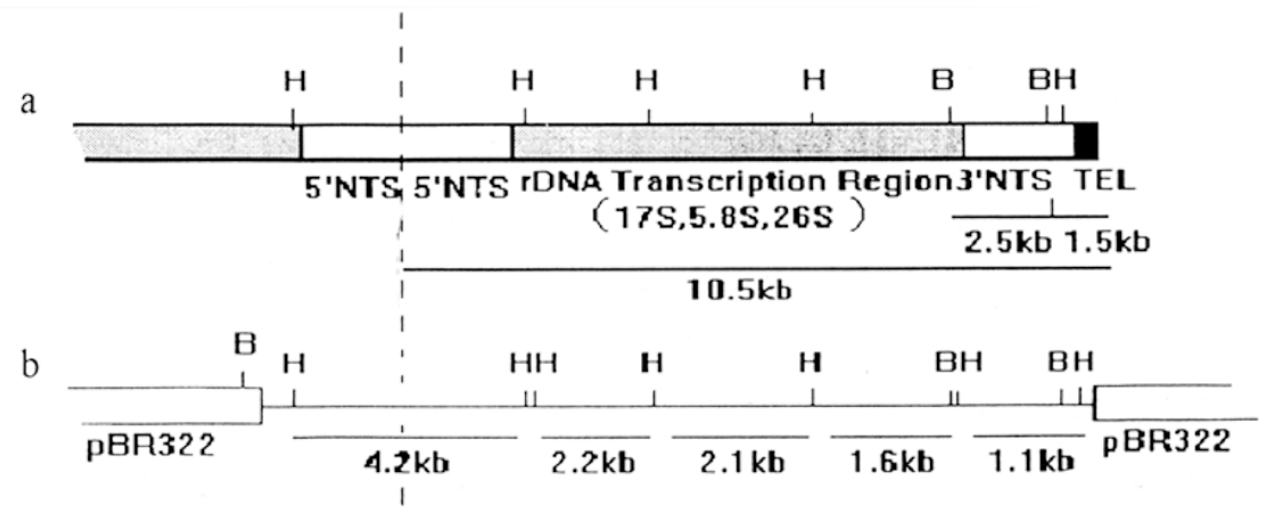

Fig 1. Structures of palindromic rDNA (a) and pRd4-1 plasmid (b) Vertical dashed line, center of the plaindrome; A nontranscription region (5'NTS) is located close to the center of the molecules. The coding regions, and the down stream to coding regions have other NTS ( 3 NTS). At both ends of the DNA, there are telomere sequences (TEL). B=BamH I, H=Hind III.

\section{Nuclear reconstitution in cell-free system}

Xenopus egg extracts were prepared by the method of Zhang et al[7]. Xenopus eggs were dejellied with $2 \%$ cysteine ( $\mathrm{pH} 7.8$ ), rinsed twice in $\mathrm{MMR}\left(0.1 M \mathrm{NaCl}, 2.0 \mathrm{~m} M \mathrm{KCl}, 1.0 \mathrm{~m} M \mathrm{MgSO}_{4}, 2.0\right.$ 


\section{rDNA and nuclear matrix}

$\mathrm{m} M \mathrm{CaCl}_{2}, 5.0 \mathrm{~m} M$ Hepes, and $0.1 \mathrm{~m} M$ EDTA, pH 7.8), activated by $0.2 \mu \mathrm{g} / \mathrm{ml} \mathrm{Ca}^{2+}$ ionophore A23187 (Sigma) in MMR, then lysed by centrifugation twice at 10,000 g for 15 min, and got the cytosol as nuclear reconstitution extracts.

$8 \mu \mathrm{g}$ rDNA was mixed with $200 \mu \mathrm{l}$ extracts and ATP-regenerating system ( $2 \mathrm{~m} M$ ATP, $20 \mathrm{mM}$ phosphocreatine and $50 \mu \mathrm{g} / \mathrm{ml}$ creatin kinase), and incubated at $22{ }^{\circ} \mathrm{C}$. About $3-4 \mathrm{~h}$ after the incubation, the assembled nuclei were observed.

\section{Electron microscopy}

\section{Epon 812 embedment section}

After incubation, the samples were fixed in $2.5 \%$ glutaraldehyde, postfixed with $2 \%$ osmium tetra oxide $\left(\mathrm{O}_{\mathrm{S}} \mathrm{O}_{4}\right)$ buffered with 0.1 $\mathrm{M}$ PBS ( $\mathrm{pH}$ 7.4) and embedded in Epon812.

Epon-embedded ultra thin sections were cut (50-60 nm) and picked up on carbon formvar coated grids.

LK4M low temperature embedment section and electron microscopy in situ hybridization

The LK4M low temperature embedding samples was fixed in freshly prepared $3 \%$ paraformaldehyde in $0.1 \mathrm{M}$ sodium cacodylate buffer ( $\mathrm{pH} 7.4$ ), containing $0.1 \%$ glutaraldehyde and $4 \%$ sucrose, for $4 \mathrm{~h}$ at $4{ }^{\circ} \mathrm{C}$. After four washes each for $15 \mathrm{~min}$ at $4{ }^{\circ} \mathrm{C}$ in $0.1 \mathrm{M}$ sodium cacodylate buffer containing $4 \%$ sucrose embedded in lowicryl K4M.

Electron microscopy in situ hybridization was carried out using method of Jiao et al[16] Lowicryl K4M-embedded ultra thin sections were cut (50-60 $\mathrm{nm}$ ) and picked up on carbon formvar-coated nickle grids. After denaturation and prehybridization, sections were hybridized by float the grids on one drop of hybridization buffer ( $50 \%$ formamide, $2 \times \mathrm{SSC}, 0.3 \%$ each of Ficoll, polyvinyl pyrrolidone (pvp), and BSA, $100 \mu \mathrm{g} / \mu \mathrm{l}$ sheared salmon sperm DNA, and $1 \mu \mathrm{g} / \mathrm{ml}$ of the probe) for 9-10 h at $37{ }^{\circ} \mathrm{C}$. After hybridization, the grid was stained with antibodies, and air dried.

For denaturation the probe and other nucleic acid components were boiled for 2 min and immediately cooled to $0{ }^{\circ} \mathrm{C}$ where they were kept until use. For control identical treatment with identical reagents was provided except that non-biotinylated pRD4-1 DNA was used instead of a biotinylated probe.

All above grids were stained with $2 \%$ aqueous uranyl acetate and lead citrate, then examined with JEM100CX.

\section{Preparation of nuclear matrix associated DNA and supernatant DNA Extraction of nuclear matrix}

Nuclear matrix was prepared according to Cai et al. with some modification[9]. The assembled nuclei were extracted in cytoskeleton buffer (CSK: $100 \mathrm{~m} M \mathrm{KCl}, 300 \mathrm{~m} M$ sucrose, $100 \mathrm{~m} M$ PIPES, pH 6.8, $3 \mathrm{mM} \mathrm{MgCl}_{2}, 1.2 \mathrm{mM}$ PMSF, 0.5\% Triton X-100) for $5 \mathrm{~min}$. Soluble proteins were removed by centrifugation at $600 \mathrm{~g}$ for $5 \mathrm{~min}$, and the pellets were extracted in RSB-Magik (42.5 mM Tris-HCl, pH 8.3, 8.5 mM NaCl, $2.6 \mathrm{~m} M \mathrm{MgCl}_{2}, 1.2 \mathrm{~m} M$ PMSF, $1 \%(\mathrm{v} / \mathrm{v})$ Tween 40, 0.5\% sodium desoxycholate) for $5 \mathrm{~min}$ and pelleted as before. The remnant pellet was resuspended in digestion buffer (the same as CSK buffer except with $50 \mathrm{mM} \mathrm{NaCl}$ instead of $\mathrm{KCl}$ ). Then ammonium sulfate was added to a final concentration of $0.25 \mathrm{M}$. After incubation for $5 \mathrm{~min}$ the sample was then centrifuged at $1000 \mathrm{~g}$ for $5 \mathrm{~min}$.

\section{Preparation of nuclear matrix-associated DNA and supernatant DNA}

The remnant pellets obtained after treatment with ammonium sulfate were resuspended in digestion buffer, and digested with $20 \mu \mathrm{g} / \mathrm{ml}$ Hind III at $37{ }^{\circ} \mathrm{C}$ for $4 \mathrm{~h}$. Nuclear matrix and supernatant were obtained by centrifugation at $4000 \mathrm{~g}$ for $5 \mathrm{~min}$ after digestion. The pellets (nuclear matrix) were resuspended in proteinase $\mathrm{K}$ buffer (10 $\mathrm{m} M$ Tris-HCl, $\mathrm{pH} 7.8,0.05 \mathrm{M}$ EDTA, 0.5 \% SDS), 
and digested with proteinase $\mathrm{K}(50 \mu \mathrm{g} / \mathrm{ml})$ at $55^{\circ} \mathrm{C}$ for $5 \mathrm{~h}$. The supernatant DNA and nuclear matrix-associated DNA were obtained by extraction with phenol: chloroform and precipitation in alcohol.

\section{Southern transfer and molecular hybridization}

For dot hybridization, we denatured the DNA samples at $95{ }^{\circ} \mathrm{C}$ for $5 \mathrm{~min}$ followed by added 4 volumes of $20 \times \mathrm{SSC}$ ( $\mathrm{SSC}: 3 \mathrm{M} \mathrm{NaCl}, 0.3 \mathrm{M}$ sodium citrate, $\mathrm{pH} 7.0$ ), and dotted them onto nitrocellulose (NC) filter according to the standard method.

For the southern analysis of plasmid DNA (pRD4-1 was digested by Hind III), run in $0.7 \%$ argose gel and transferred onto the NC filter.

The supernatant DNA and the nuclear matrix associated DNA were labeled with ${ }^{32} \mathrm{p}-\mathrm{dCTP}$ by random primer labeling and used as probe.

Hybridization was performed by the standard protocol.

\section{RESULTS}

\section{Nuclear assembly with purified rDNA form Tetrahymena macronuclei}

rDNA was isolated and purified by the method established by T. Cech with modification[15]. The rRNA genes (rDNA) in the macronucleus of Tetrahymena are linear, extrachromosomal molecules containing about 21,000 bp of DNA with a palindromic sequences symmetry. Here we showed the gel electrophoresis of rDNA BamH I restriction map (Fig 2).

Fig 2. Restriction map of rDNA fragments, a, $\gamma$ phage DNA Hind III fragments are used as molecular weight control; b, rDNA purified from the macronuclei of Tetrahymena, $\sim 20 \mathrm{~kb}$; c, the restriction map of rDNA digested by $\mathrm{BamH}$ I, one $14 \mathrm{~kb}$, two $4 \mathrm{~kb}$ or two $2.5 \mathrm{~kb}$ and two $1.5 \mathrm{~kb}$ fragments; d, purified pRd4-1, 15.6kb; e. Hind III digestion of $\mathrm{pRd} 4-1$ generates $4.2 \mathrm{~kb}, 3 \mathrm{~kb}, 2.2 \mathrm{~kb}, 1.6 \mathrm{~kb}$ and $1.1 \mathrm{~kb}$ fragments, the $4.2 \mathrm{~kb}$ fragment contains the 5'NTS, the coding sequences and 3'NTS are all smaller than $2.2 \mathrm{~kb}$.

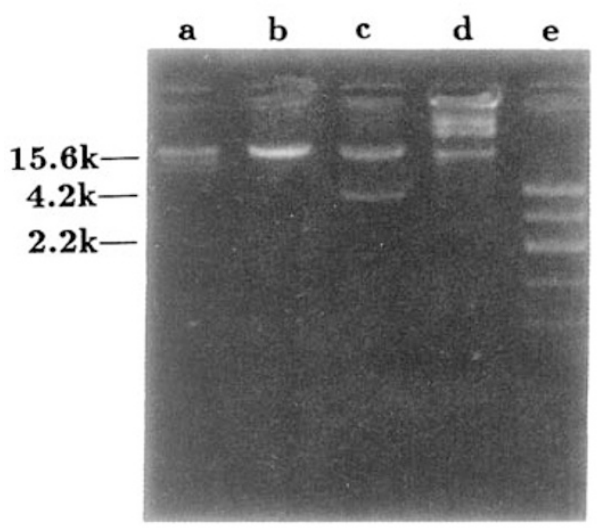

After incubated in Xenopus egg extracts, the rDNA could induce the formation of nuclear like structure (Fig 4). Nuclear reconstitution occurred in steps and the ultrastructure of the assembled nuclei was similiar to that induced by other exogenous DNA or chromatin previously reported (Fig 3)[6]. 

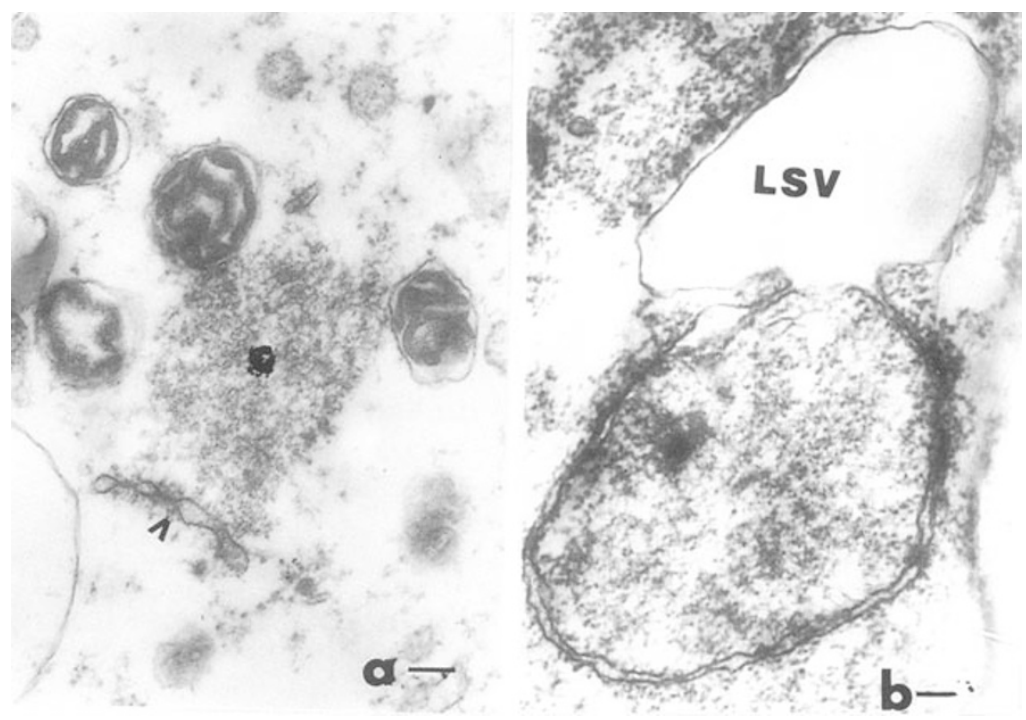

Fig 3. After incubated in Xenopus egg extracts for $4 \mathrm{~h}$, rDNA could induce the formation of nuclear like structure, as shown by electron microscopy ultrathin section. Nuclear reconstitution occurred in steps and the ultra structrue of the assembled nuclei was similar to what we reported previously about the reconstitution process and nuclear structure induced by other exogenous DNA or chromatin, a. Chromatin-like structure (C) induced by rDNA was formed and some membrane (arrow head) being attached to the surface of the chromatin, b. A large smooth membrane vesicle (LSV) joins to the formed nuclear membrane. Bar $=1 \mu \mathrm{m}$

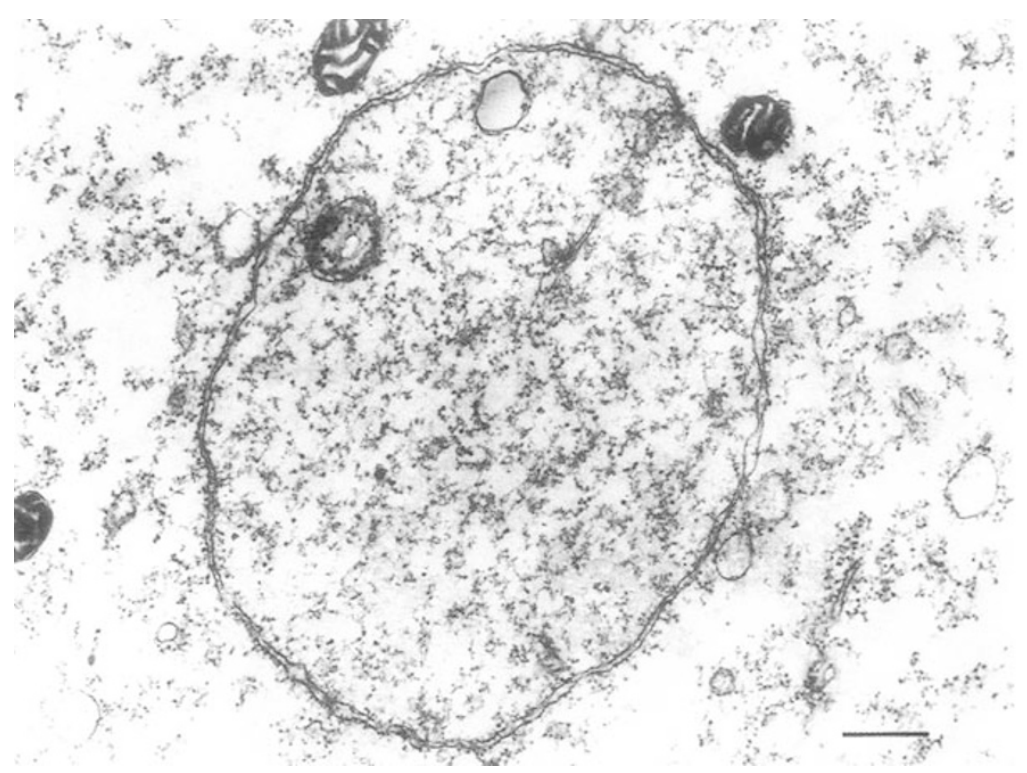

Fig 4. Electron rnicrograph of the assembled nucleus, showing the typical double nuclear membrane and chromatin-like structure. $\mathrm{Bar}=1 \mu \mathrm{m}$ 
Analysis of the DNA components in the assembled nuclei

DAPI staining showed after $3 \mathrm{~h}$ incubation most rDNA had assembled into nuclei (Fig 5, insert or inset). We further visualized the rDNA molecular in the nuclei at high resolution using nonisotopic electronmicroscopy in situ hybridization. After hybridization, the biotinylated hybrids were detected by anti-biotin antibodies in consort with the second antibody conjugated with colloidal gold (10 $\mathrm{nm}$ in diameter). The gold particles observed were mainly distributed in the nuclear-like structure as shown in Fig 5, indicating that the assembled nuclei contained rDNA molecules.

\section{rDNA is associated with nuclear matrix of assembled nuclear}

Wang et a1.(1994) showed that even after excessive digestion with DNAase I (50 $\mu \mathrm{g} / \mathrm{ml}$ ) for $6 \mathrm{~h}$, there still 9\% of total DNA left binding to nuclear matrix[2]. They proposed that that DNA contain some specific regions that are closely associated with nuclear matrix. As mentioned before, Cai proved that there is a nuclear matrix filament network in the nuclei induced by exogenous DNA in the Xenopus

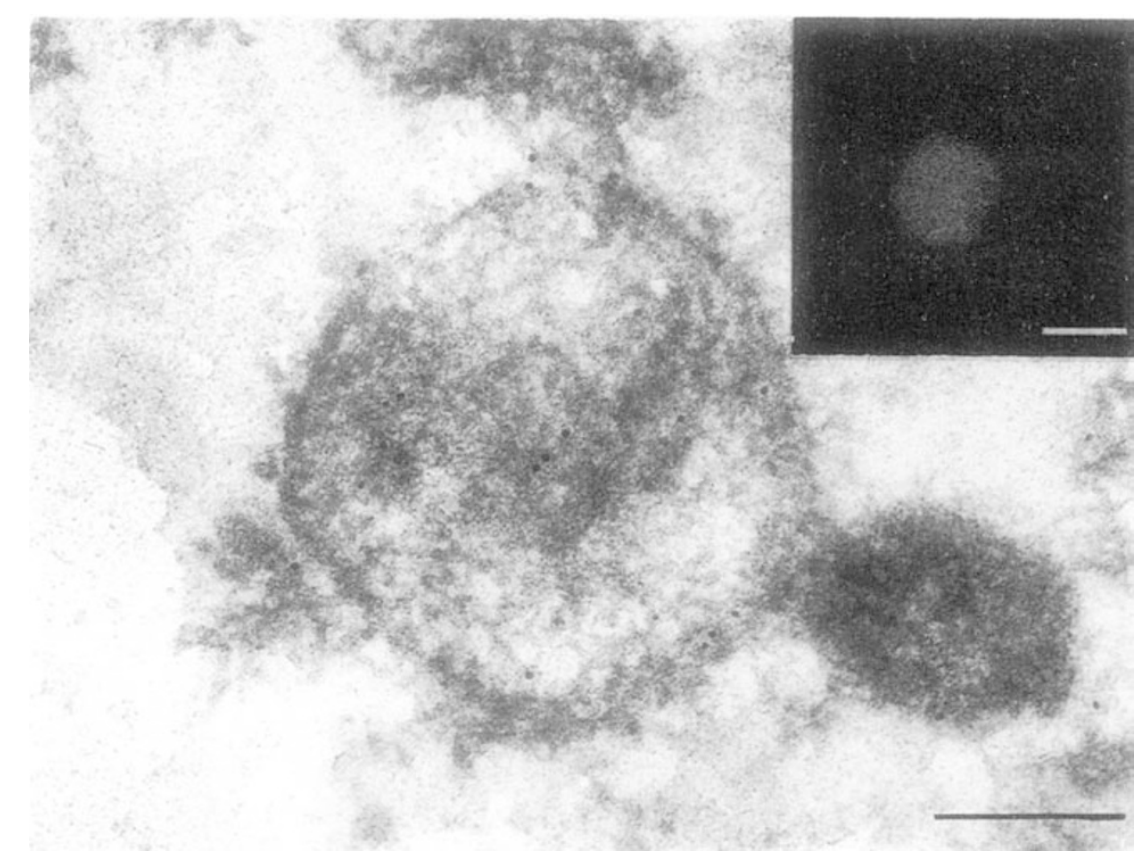

Fig 5. A Lowicryl $\mathrm{K}_{4} \mathrm{M}$-embedment section of an assembled nucleus, hybridized with biotinylated pRd4-1 probes containing rDNA, detected by anti-biotin and gold (10 $\mathrm{nm}$ )-labeled secondary antibodies. Gold particles were distributed over the nucleus, mainly over the dense-stained regions. Bar $=1 \mu \mathrm{m}$. inst. After $4 \mathrm{~h}$ 's incubation at $22{ }^{\circ} \mathrm{C}$, the specimen was fixed and stained by DNA specific fluorescent dye (DAPI). Most DNA has been assembled into nucleus- like structure. Bar $=5 \mu \mathrm{m}$. 


\section{rDNA and nuclear matrix}

egg extracts. We wonder if the exogenous DNA also has some parts that may have some specific binding affinity with the nuclear matrix in Xenopus cell-free system. The NM system was isolated from the nuclei assembled from rDNA, then excessively digested by DNase I to get residual DNA. Dot hybridization with pRD4-1 containing rDNA showed the residual DNA in the NM was consisted of rDNA (Fig 6).

Fig 6. Dot hybridization with ${ }^{32} \mathrm{P}-\mathrm{dCTP}$ labeled pRd4-1 probe, showing residual rDNA in the nuclear matrix of the in vitro assembled nuclei. 1, rDNA as positive control; 2 , residual DNA in the nuclear matrix $(\mathrm{NM}) ; 3, \lambda$ phage DNA as negative control.
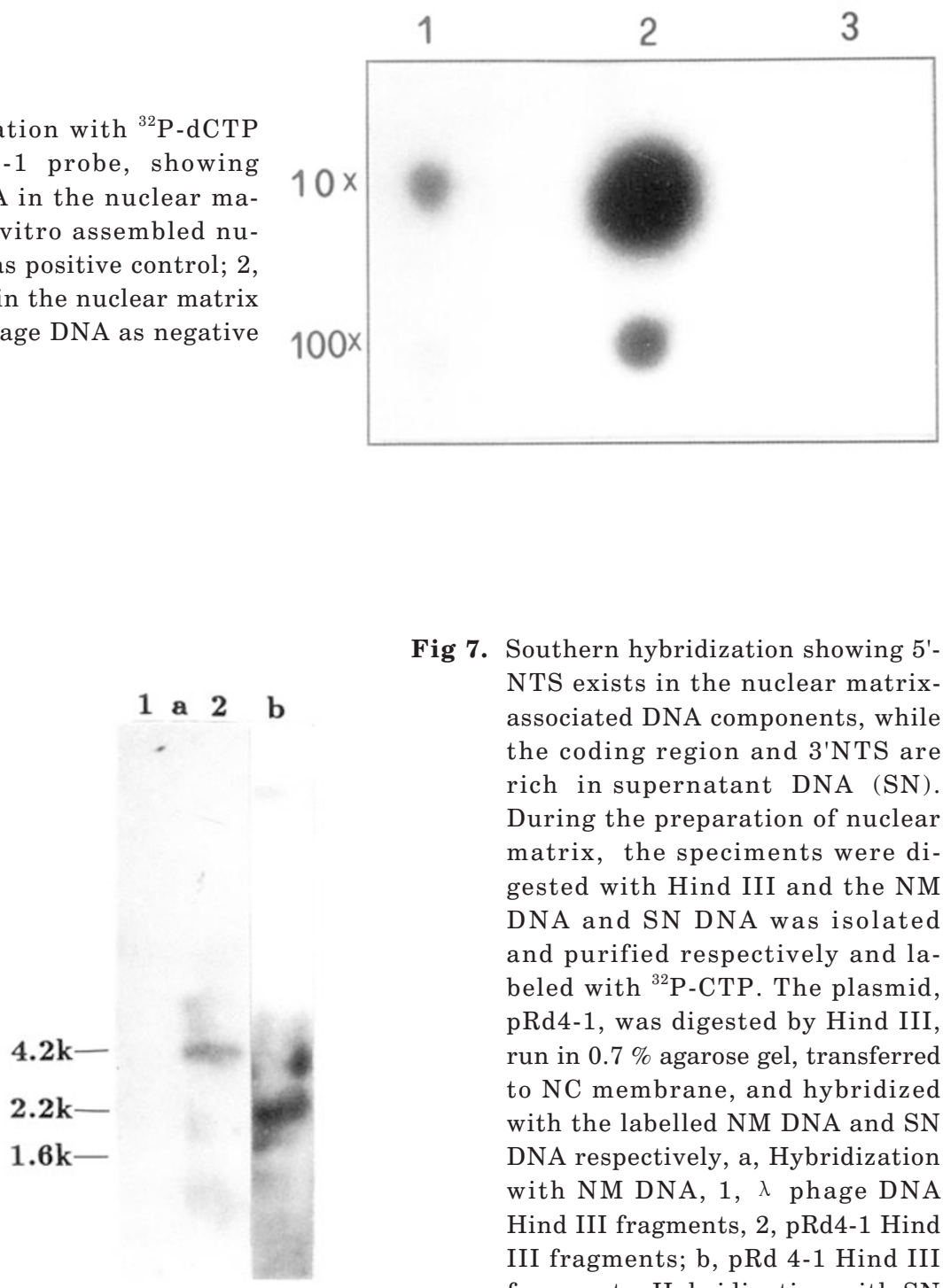

Fig 7. Southern hybridization showing 5'NTS exists in the nuclear matrixassociated DNA components, while the coding region and 3 'NTS are rich in supernatant DNA (SN). During the preparation of nuclear matrix, the speciments were digested with Hind III and the NM DNA and SN DNA was isolated and purified respectively and labeled with ${ }^{32}$ P-CTP. The plasmid, pRd4-1, was digested by Hind III, run in $0.7 \%$ agarose gel, transferred to NC membrane, and hybridized with the labelled NM DNA and SN DNA respectively, a, Hybridization with NM DNA, 1, $\lambda$ phage DNA Hind III fragments, 2, pRd4-1 Hind III fragments; b, pRd 4-1 Hind III fragments, Hybridization with SN DNA. 
Comparison of the binding affinity of different regions of $r D N A$ with the NM system

Is the association of rDNA with nuclear matrix random or specific? The NM system was isolated and, digested with Hind III for $3-4 \mathrm{~h}$ at $37{ }^{\circ} \mathrm{C}$ to get nuclear matrix associated DNA (NM DNA) and supernatant DNA (SN DNA). Same amount of both DNA was labeled by ${ }^{32} \mathrm{P}$-dCTP and used as probes in Southern blotting with fragments of pRd4-1 digested by Hind III respectively (Fig 7). Fig 7 showed the fragments containing 5 'NTS reacted with NM DNA positively, while the fragments containing the coding region and 3 'NTS were rich in SN DNA. These results suggested that the 5 'NTS was closely associated with nuclear matrix, while the transcriptional region and 3'NTS had no relation to the nuclear matrix.

\section{DISCUSSION}

In the 5'NTS of each T. shanghaiensis rDNA molecule, there are three kinds conserved repetitive sequence named as type I-III sequences respectively[17]. Many previous works have shown that those repetitive sequences are the components of replication origin or transcription promoter and involve in the initiation of transcription or control of replication[18, 19]. Further analysis of these sequences showed that they are highly AT rich and have DNAase I sensitive sites. These characteristics of the regions in 5'NTS suggest that they may have binding affinity with nuclear matrix and may play important roles in chromatin organization and control of gene replication and transcription. But very little is known about this DNA-protein interaction in the 5'NTS. Do the proteins involve in transcription and replication interacts with these regions in transient manner, or set up some stable DNA-protein interaction at these regions to help the organization of chromatin and nuclei and serve as recognition sites for transcription or replication factors?

Previous works have shown that embryonic development in Xenopus laevis starts with a period of rapid cleavage without observable RNA transcription[20]. We found that nucleoli (indication of rRNA gene transcription) could not form even after active NOR (nucleoli organizer) was introduced into Xenopus egg extracts because of rRNA transcription inhibition[21]. Many workers have also shown that no specific sequences are needed for inducing nuclear assembly in Xenopus egg extracts. Unlike the replication in yeast which needs specific sequence such as ARS-containing sequences for DNA replication, the replication in assembled nuclei induced by exogenous DNA in Xenopus eggs extract can occur without specific sequence[22]. Here we show that although no specific sequence of DNA is needed for inducing the reconstruction of nuclei in Xenopus egg extracts or DNA replication in the assembled nuclei, and no transcription occurs in those nuclei, some specific sequences in rDNA 5 'NTS still hold their binding affinity to some non-histone proteins of nuclear matrix in the reassembled nuclei. So we propose that they are some stable DNA-protein interactions. They are related with the DNA sequence, the DNA structure and 


\section{rDNA and nuclear matrix}

some nuclear matrix proteins, nomatter whether or not the nuclei are in replication or transcription. But during replication and transcription, those bindings can help to control the frequency of replication and enhance the initiation of transcription. The details of the interactions between DNA and proteins, such as which proteins and the defined specific sequences are involved in and their roles in chromosome organization and nuclei formation, are what we want to know in our future work.

\section{A CKNO WLED GEMENTS}

1. This work was supported by a grant from the National Natural Sciences Foundatrion.

2. We are grateful to Ms. Jinhua LIANG for help in preparing experimental materials.

\section{REFERENCES}

[1] Berezney R, Coffey D. Identification of a nuclear protein matrix. Biochem Biophys Res Commun 1974; 60:1410-9.

[2] Wang GS, Luo W J, Pan W J, Ding MX, Zhai ZH. Association of chromosomal telomere DNA with nuclear matrix in HeLa cell. Science in China (Series B) 1994; 37(6):691-9.

[3] Zhai ZH, Chen F, Nickerson JA, Penman S. Association of adenovirus DNA transcribed activity with nuclear matrix of host cells. Science in China (Series B) 1989; 32(2):176-84.

[4] Sze LC, Yao Sl, Yang TF, Wang SM. A cytological study on the injected homologous deoxyribose nucleoprotein in the Rana mogromaculata eggs. Science Record New Ser 1959; 3:149-54.

[5] Lohka, M J, Masui Y. Rormation in vitro of sperm pronuclei and mitotic chromosomes induced by amphibian ooplasmic components. Science 1983; 220:719-21.

[6] Newport J. Nuclear reconstitution in vitro: stages of assembly around protein-free DNA. Cell 1987; 48:205-217.

[7] Zhang CM, Qu J, Liang JH, Zhai ZH. Biological activity assays of cell-free reassembled nuclei. Science in China (Series B) 1995; 38(9):1076-83.

[8] Finlay DR, Fprbes D. Reconstitution of biochemically altered nuclear pores: transport can be eliminated and restored. Cell 1990; 60:17-

[9] Cai ST, Zhai ZH. Nuclear matrix in the nucleus assembled in vitro. China Science Bulletin 1993; 38(18):1567-71.

[10] Pardoll DM, Vogelstein B, Coffey DS. A fix site of DNA replication in eukaryotic cells. Cell 1980; 19:527-36.

[11] Jackson DA, Cook PR. Replication occurs at a nucleoskeleton. EMBO J 1984; 5:1403-10.

[12] Smith HC, Rothblum LI. Ribosome DNA sequence attached to the nuclear matrix. Biochem Genet 1987; 25:863-79.

[13] Luo W J, Jiao R J, Zhai ZH. Relation between the rRNA gene and nuclear matrix in Tetrahymena shanghaiensis macronucleus. Chinese Science Bulletin 1995; 40(18):1711-6.

[14] Fen SL. Tetrahymena S1- a new species of Tetrahymena shanghainesis. Acta Zoological Sinica 1988; 34(1):42-50.

[15] Maniatis T. Molecular Cloning. 1982; 150-172. Cold Spring Harbor Laboratory.

[16] Jiao R J, Yu WD, Ding MX, Zhai ZH. Localization of adenovirus DNA by in situ hybridization electron microscopy. Microscopy Research and Technique 1992; 21:23-31.

[17] Challoner PB, Amin AA, Pearlman RE, Blackburn EH. Conserved arrangements of repeated DNA sequences in nontranscribed spacers of ciliate ribosomal RNAgenes: evidence for molecular 
coevolution. Nucl Acids Res 1985; 13:2661-80.

[18] Nile EG. Identification of multiple sites in the promoter region of the Tetrahymena pyriformis rRNA gene which bind the Escherichia coli catabolite regulatory protein. J Biol Chem 1985; 260:672-8.

[19] Palen TE, Cech TE. Chromatin structure at the regions and transcription-initiantion regions of the ribosomal RNA genes of Tetrahymena. Cell 1984; 36:933-42.

[20] Newport J, Kirschner M. A major developmental transition in early Xenopus embryos: II. control of the onset of transcription. Cell 1982; 30:687-96.

[21] Chen Y, Zhang B, Luo W J, Zhai ZH. Cell-free nuclear assembly induced by nucleoli and demembranated macronuclei from Tetrahymena shanghaiensis. Acta Biologiae Experimentalis Sinica 1996; 29(3):255-67.

[22] Mechali M, Kearsey S. Lack of specific sequence requirement for DNA replication in Xenopus eggs compared with high sequence specificity in Yeast. Cell 1984; 38:55-64.

Received 31-3-1997. Revised 7-5-1997. Accepted 6-6-1997 